\title{
The (love \& hate) role of entropy in process metallurgy
}

\author{
Halvard Tveit ${ }^{1, *}$ and Leiv Kolbeinsen ${ }^{2}$ \\ ${ }^{1}$ Elkem, Trondheim, Norway \\ 2 NTNU, Norwegian University of Science and Technology, Trondheim, Norway
}

Received: 20 August 2019 / Accepted: 13 December 2019

\begin{abstract}
Process metallurgy is the basis for the production, refining and recycling of metals and is based on knowledge of transport phenomena, thermodynamics and reaction kinetics, and of their interaction in hightemperature, heterogeneous metallurgical processes. The entropy concept is crucial in describing such systems, but, because entropy is not directly observable, some effort is required to grasp the role of entropy in process metallurgy. In this paper, we will give some examples of how entropy has a positive effect on efforts to reach the process objectives in some cases, while in other cases, entropy acts in contradiction to the desired results. In order to do this, it is necessary to have a closer look at both the entropy concept itself as well as at other functions like free energy and exergy since they encompass entropy. The chosen case is the production of silicon. It is the huge entropy change in the process that is utilized. The case is not chosen arbitrary. Indeed, it is the authors' strong belief that silicon will be one of the foundations for the environmental and energy future planned for in the "Parisagreement". We will also explore relatively recent research in physics and thermodynamics that led to the description of the concepts like "dissipative systems and structures". Dissipative systems are thermodynamically open systems, operating out of, and often far from thermodynamic equilibrium and exhibit dynamical regimes that are in some sense in a reproducible self-organized steady state. Such structures can arise almost everywhere provided this structure, feeding on low entropy resources, dissipates entropy generated in the form of heat and waste material in parallel with the wanted products/results. Examples range from metallurgical processes to the emergence of industrial symbiosis.
\end{abstract}

Keywords: silicon / silicon process / silicon use / energy / entropy / exergy / COP 21

\section{Introduction (based mainly on [1])}

All processes of macroscopic change are generally irreversible. Examples include natural processes, such as the oxidation of metals, as well as technical processes, such as the burning of fossil fuels in combustion engines or for that matter the production of metals from their oxides. The entropy concept, coined in thermodynamics to capture this fact of nature, allows making quantitative statements about the efficiency of energetic and material transformations. By now, the original notion of entropy has been greatly generalized and applied in many different contexts outside classical thermodynamics. There exist a number of alternative definitions of the term, not all of them formally consistent with each other. Because the entropy concept is manifold, it is also complex and difficult to understand. As a physical quantity, entropy is not much different from other extensive quantities, like energy and mass, except that the entropy of a system plus its

\footnotetext{
* e-mail: halvard.tveit@elkem.no
}

environment cannot decrease. Entropy is always the entropy of 'something', like the entropy of one litre of water, a kilogram of salt or a joule of electromagnetic radiation. Therefore, it makes perfect sense to speak of the entropy content of a material or of an energy reservoir.

"Free energy", e.g. Gibb's free energy, "Exergy" and "Available energy" correspond to the useful part of energy, which can be transformed into mechanical or chemical work. It thus combines the insights from both the First Law of Thermodynamics (conservation of energy) and the Second Law of Thermodynamics (generation of entropy). The difference between these variables is mainly their state of reference. Gibb's free energy refers to the pure elements in their stable state as "Zero". For Exergy, on the other hand, the element's or compound's stable state in nature is used as reference. This latter reference state is more difficult to define.

Whenever entropy increases, the opportunity to convert some energy into work is lost. For example, there is an increase in entropy when hot and cold water are mixed. Then, warm water which results cannot be separated into a hot layer and a cold layer. There has 

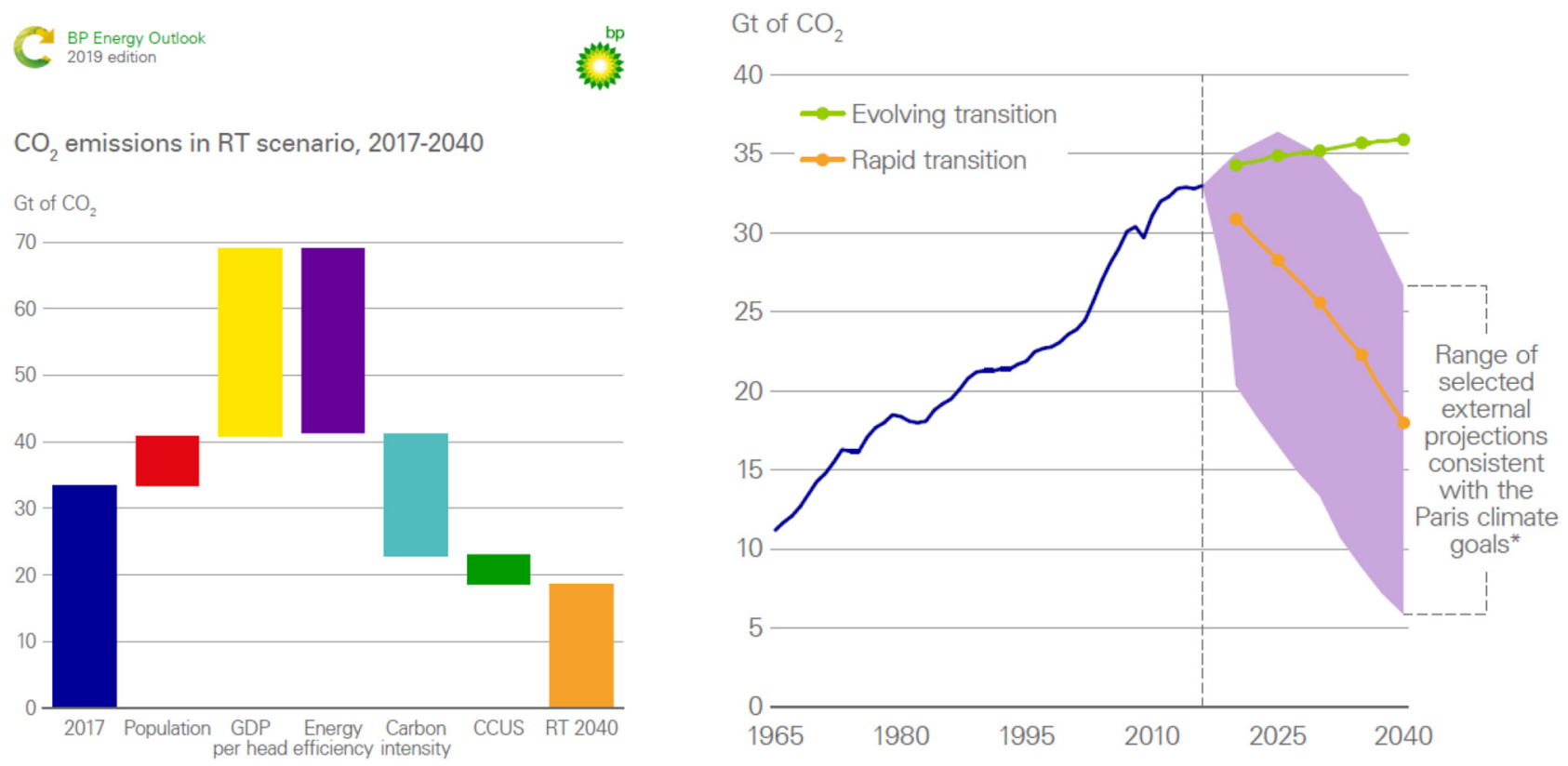

Fig. 1. Increase in $\mathrm{CO}_{2}$ emission due to increased population and economic growth [2].

been no loss of energy but some of the energy is no longer available for conversion into work. Therefore, increase in entropy means degradation of energy:

- from a higher level where more work can be extracted;

- to a lower level at which less or no useful work can be done.

The energy in a sense is degraded, going from a more orderly form to a less orderly form; eventually ending up as thermal energy.

Mixing of different materials or compounds always cause an increase in entropy. Accordingly, to un-mix a mixture implies decreasing the entropy of that system. The only way to do this is to use energy from outside of the system, and in thermodynamics, this is the environment of the system. Mixing is often very easy; separation or unmixing is often much more difficult and energy demanding. To produce $\mathrm{FeSi}$, e.g. an alloy of $\mathrm{Fe}$ and $\mathrm{Si}$ is easier than to produce pure silicon. On the other hand, the removal of impurities appearing in low concentrations or the capture of $\mathrm{CO}_{2}$ from gases, where its partial pressures is low, is energy (work)-demanding and causes high costs per unit material removed.

The $\Delta$-sign is used to designate changes in variables as $\mathrm{G}, \mathrm{S}$ and $\mathrm{H}$ for a reaction, i.e. conversion of reactants to products, at a constant temperature. $\Delta \mathrm{H}$ is thus the thermal energy that must be supplied (endothermic reaction; positive $\Delta \mathrm{H}$ ) or removed (exothermic reaction; negative $\Delta \mathrm{H}$ ) to sustain constant temperature when a reaction proceeds.

\section{The Paris Agreement - and the consequences for the energy usage}

In Paris, on 12 December 2015, Parties to the UNFCCC reached a landmark agreement to combat climate change and to accelerate and intensify the actions and investments needed for a sustainable low-carbon future [9].

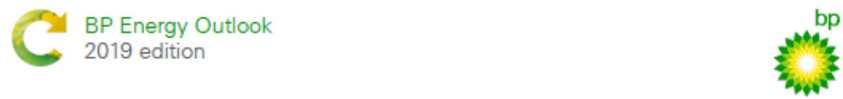

Primary energy consumption by fuel

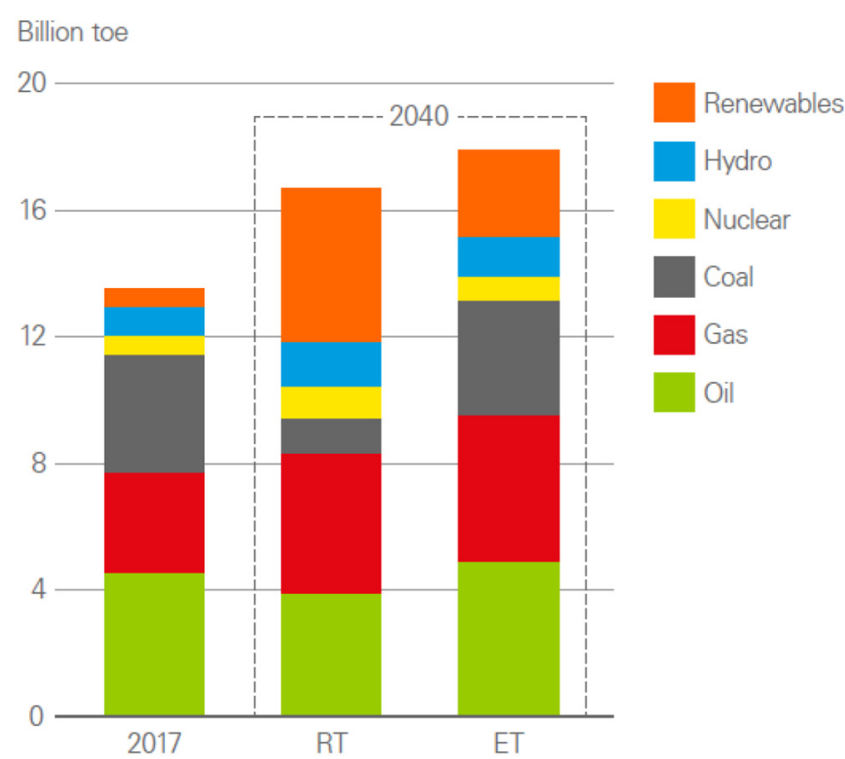

Fig. 2. Consequences for the primary energy consumption by fuel [2].

In spite of some doubts about the necessity and the possibility to reach the agreement, many industrial and academic stakeholders are building the technical and economic consequences of the Paris agreement into their visions, strategies and development work.

The most dramatic change will be in the use of energy as shown in Figures 1 and 2. 

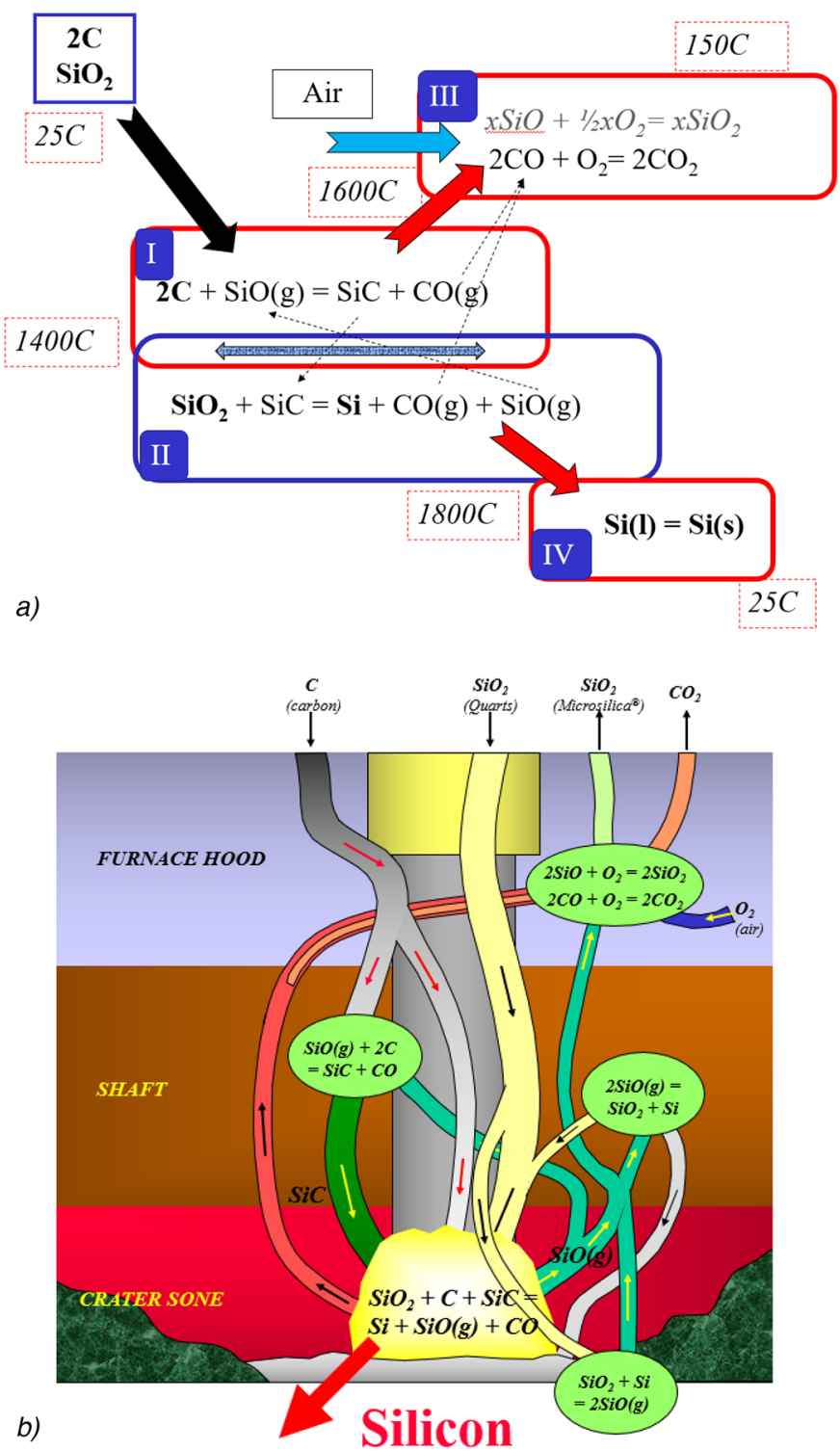

Fig. 3. a): principal production steps in a silicon process; b): artistic version of same.

Figure 1 shows the increase in $\mathrm{CO}_{2}$ emission due to increased population and a growing economy - and the necessary reduction in emissions in the form of greater efficiency, fuel switching and use of CCUS (RT means rapid transition scenarios). The consequent reduction is shown on the right-hand side of the figure 3 .

Figure 2 shows the consequences for the primary energy consumption by fuel. The wanted Rapid transition scenario requires a reduction in coal consumption - and an even more pronounced increase in the use of renewable energy here an $800 \%$ increase. The evolving transition (ET) to the right will not yield the expected reduction in $\mathrm{CO}_{2}$ emission [2].

All scenarios shown in the BP energy outlook show a rapid increase in the use of renewable energy sources - and a strong reduction in the use of fossil carbon, especially of coal.

\section{Silicon - the metalloid hero faces new assignments for humanity}

Silicon is the second-most abundant element in the earth's crust after oxygen. In natural form, it is almost exclusively combined with oxygen as fairly pure silicon dioxide and silicates. Silicon dioxide as flint was the major tool for man in the Lithic Ages, and, later, silicates have been essential in materials such as ceramics and glass. Silicon was recognized as an element in the early 19 th century and was produced on an industrial scale as an element or in alloys by the end of the century.

Silicon is a metalloid with extreme bonding qualities and easy doping possibilities. The main challenge is to make metallic grade silicon - i.e. separate silicon and oxide in the $\mathrm{SiO}_{2}$-formation. The very stable bonding of $\mathrm{O}-\mathrm{Si}-\mathrm{O}$ is due to the ionic size of silicon that needs to share 4 electrons in the $3^{\text {rd }}$ electron shell - but is only able to share 1 electron with each oxygen atom.

Silicon and its alloys were rather unknown to the public before the computer industry made it famous and the naming of Silicon Valley in 1971 became a symbol for the modern world.

The development of usages for silicon has been spectacular ever since - both is the use of silicones and in computer chips. Silicon is now an important part of daily life of most human being on Earth - whether they know about it or not.

The new assignments for silicon will be to contribute to a happy outcome of the triple whammy facing the soon to be 10 billion people in human society:

- increasing use of energy;

- possible future constraint in the supply of electric power; - possible serious environmental consequences in application of the some of the main energy sources.

Silicon will play an important role in dealing with these problems. Silicon is used in the production of lightweight materials for transport, silicones as well, and is related to an important computer development. The direct use of silicon in the power production will be in solar cells and possibly also in an important development of a new type of batteries needed in the change towards a solar-based power supply in general.

\section{The silicon processes}

Figure 3 shows the principal production steps of a silicon process. The red steps are exothermic - but the blue reaction zone both requires high temperature (above $1800^{\circ} \mathrm{C}$ ) and a continuous supply of energy. The only industrial process used today is submerged arc furnace with electrical energy through carbon electrodes.

The process for making silicon today requires highenergy input, high process temperature and the use of carbon as a reducing agent. The main overall reaction equation is:

$$
\mathrm{SiO}_{2}+2 \mathrm{C}=\mathrm{Si}+2 \mathrm{CO}(\mathrm{g}) . \quad \mathrm{Rx}(1)
$$


Table 1. Thermodynamic reaction data, $\Delta \mathrm{H}, \Delta \mathrm{G} \& \Delta \mathrm{S}$, for the total reaction $\operatorname{Rx}(1)$.

\begin{tabular}{llll}
\hline \multicolumn{2}{l}{ Reaction equation } \\
$\mathrm{SiO}_{2}+2 \mathrm{C}=\mathrm{Si}+2 \mathrm{CO}(\mathrm{g})(1)$ & & \\
$\begin{array}{l}\text { Reaction data } \\
\mathrm{T}\end{array}$ & $\mathrm{H}$ & $\Delta \mathrm{S}$ & $\Delta \mathrm{G}$ \\
${ }^{\circ} \mathrm{C}$ & $\mathrm{kJ}$ & $\mathrm{J} / \mathrm{K}$ & $\mathrm{kJ}$ \\
\hline 1500,000 & 712,760 & 367,347 & 61,398 \\
1600,000 & 710,357 & 366,029 & 24,730 \\
1700,000 & 707,927 & 364,765 & $-11,809$ \\
1800,000 & 695,201 & 358,410 & $-47,835$ \\
\hline
\end{tabular}

Table 2. Thermodynamic reaction data, $\Delta \mathrm{H}, \Delta \mathrm{G} \& \Delta \mathrm{S}$, for the direct $\mathrm{SiC}$ production $\mathrm{Rx}(2)$.

\begin{tabular}{|c|c|c|c|}
\hline \multicolumn{4}{|c|}{$\begin{array}{l}\text { Reaction equation } \\
\mathrm{Si}+\mathrm{C}=\mathrm{SiC}(2) \\
\text { Reaction data }\end{array}$} \\
\hline 1600,000 & $-122,8$ & $-38,5$ & $-50,6$ \\
\hline 1700,000 & $-122,8$ & $-38,5$ & $-46,8$ \\
\hline 1800,000 & $-122,7$ & $-38,5$ & $-42,9$ \\
\hline
\end{tabular}

Table 1 shows the total reaction equation for silicon production. The conversion from the very endothermic reaction to a negative Gibbs energy is due to the high entropy. The reason is that the reactants are in a condensed phase - and the products are liquid and gas phases. High process temperature and continuous energy supply is the key to overcoming a very stubborn $\Delta \mathrm{H}$.

Using the HSC thermodynamic program [3], the result looks promising. Due to its very high entropy change, reaction (1) seems to be able to generate the wanted elementary silicon. Unfortunately, the combination of C and $\mathrm{Si}$ will react further, generate $\mathrm{SiC}$ and thus destroy any possible production of silicon.

$$
\mathrm{Si}+\mathrm{C}=\mathrm{SiC} . \quad \mathrm{Rx}(2)
$$

Table 2 shows the reaction equation for the $\mathrm{SiC}$. This table shows that the silicon will react to $\mathrm{SiC}$ and reverse the wanted result in the simple reaction (1) above. Entropy generation by this reaction is virtually independent of temperature since no gas is consumed or produced, and no phase changes occur either in reactants or products.

The solution to the process is to design a silicon furnace where the production of $\mathrm{SiC}$ is separated from the production of silicon. The added carbon reacts in the upper part of the silicon furnace to $\mathrm{SiC}$ and $\mathrm{CO}$ :

$$
\mathrm{SiO}(\mathrm{g})+2 \mathrm{C}=\mathrm{SiC}+\mathrm{CO}(\mathrm{g}) . \quad \mathrm{Rx}(3)
$$

Table 3. Thermodynamic reaction data, $\Delta \mathrm{H}, \Delta \mathrm{G} \& \Delta \mathrm{S}$, for $\mathrm{SiC}$ production via $\mathrm{SiO} \mathrm{Rx}(3)$.

\begin{tabular}{llll}
\hline \multicolumn{4}{l}{ Reaction equation } \\
$\mathrm{SiO}(\mathrm{g})+2 \mathrm{C}=\mathrm{SiC}+\mathrm{CO}(\mathrm{g})(3)$ \\
Reaction data \\
$\mathrm{T}$ & $\mathrm{H} \mathrm{H}$ & $\Delta \mathrm{S}$ & \\
$\mathrm{T}^{\circ} \mathrm{C}$ & $\mathrm{kJ}$ & $\mathrm{J} / \mathrm{K}$ & $\mathrm{kJ}$ \\
\hline 1600,000 & $-74,561$ & $-0,835$ & $-72,997$ \\
1700,000 & $-74,402$ & $-0,752$ & $-72,913$ \\
1300,000 & $-74,247$ & $-0,675$ & $-72,347$ \\
\hline
\end{tabular}

Table 4. Thermodynamic reaction data, $\Delta \mathrm{H}, \Delta \mathrm{G} \& \Delta \mathrm{S}$, for the silicon producing $\mathrm{Rx}(4)$.

Reaction equation

$\mathrm{SiO}_{2}+\mathrm{SiC}=\mathrm{Si}+\mathrm{SiO}(\mathrm{g})+\mathrm{CO}(\mathrm{g})(4)$

Reaction data

\begin{tabular}{llll}
$\begin{array}{lll}\mathrm{T} \\
{ }^{\circ} \mathrm{C}\end{array}$ & $\begin{array}{l}\Delta \mathrm{H} \\
\mathrm{kJ}\end{array}$ & $\begin{array}{l}\Delta \mathrm{S} \\
\mathrm{J} / \mathrm{K}\end{array}$ & \multicolumn{1}{c}{$\begin{array}{l}\Delta \mathrm{G} \\
\mathrm{kJ}\end{array}$} \\
\hline 1800,000 & 769,448 & 359,085 & 25,011 \\
1900,000 & 765,919 & 357,422 & $-10,814$ \\
2000,000 & 762,382 & 355,831 & $-46,476$ \\
\hline
\end{tabular}

Table 3 shows the production of $\mathrm{SiC}$ in the upper part of the silicon furnace. Entropy generation by this reaction depends strongly on temperature.

Table 4 shows the silicon production in the reaction zone of the silicon furnace. The reaction is highly endothermic and requires a temperature above $1870^{\circ} \mathrm{C}$, the temperature where $\Delta \mathrm{G}$ becomes negative. The reason for the successful silicon production is the very high entropy generation due to condensed reactants while products are liquid and gas phase.

The metal production notably is accompanied by an enormous production of gas, and this is associated with a simultaneous high entropy generation.

$$
\mathrm{SiO}_{2}+\mathrm{SiC}=\mathrm{Si}+\mathrm{SiO}(\mathrm{g})+\mathrm{CO}(\mathrm{g}) . \quad \mathrm{Rx}(4)
$$

As shown in $\operatorname{Rx}(4)$ above, it is the combination of very high entropy due to solid state reactants and gaseous products that make the Gibbs energy negative and the production of elementary silicon possible.

There are not many suitable substitutes for carbon as a reducing agent. Hydrogen has the disadvantage to be gaseous as reactant - and the general reaction $\mathrm{Rx}(5)$ gives only positive Gibbs energy up to $3000^{\circ} \mathrm{C}$ - compare with $\operatorname{Rx}(1)$ :

$$
2 \mathrm{H}_{2}(\mathrm{~g})+\mathrm{SiO}_{2}=\mathrm{Si}+2 \mathrm{H}_{2} \mathrm{O}(\mathrm{g}) . \quad \mathrm{Rx}(5)
$$


Table 5. Thermodynamic reaction data, $\Delta \mathrm{H}, \Delta \mathrm{G} \& \Delta \mathrm{S}$, for $\operatorname{Rx}(5)$.

\begin{tabular}{|c|c|c|c|c|}
\hline \multicolumn{5}{|c|}{$\begin{array}{l}\text { Reaction equation } \\
\mathrm{SiO}_{2}+2 \mathrm{H}_{2}(\mathrm{~g})=\mathrm{Si}+2 \mathrm{H}_{2} \mathrm{O}(\mathrm{g}) \\
\text { Reaction data }\end{array}$} \\
\hline${ }^{\mathrm{T}}$ & $\Delta \mathrm{H}$ & $\Delta \mathrm{S}$ & $\Delta \mathrm{G}$ & $\mathrm{K}$ \\
\hline & & & & \\
\hline 1500,000 & 445,505 & 83,486 & 297,472 & 1,722E-009 \\
\hline 2000,000 & 427,568 & 74,584 & 258,027 & 1,170E-006 \\
\hline 2500,000 & 418,638 & 71,026 & 221,673 & $6,672 \mathrm{E}-005$ \\
\hline 3000,000 & 410,553 & 68,342 & 186,859 & $1,042 \mathrm{E}-003$ \\
\hline
\end{tabular}

Table 5 indicates the challenge to find other reducing agents than carbon. Hydrogen will not give a negative Gibbs energy up to $3000^{\circ} \mathrm{C}$. The main reason is the relative low entropy change due to equal number gas phase moles both as reactants and products.

\section{The exergy destruction in silicon production}

The main environmental challenges for the silicon production are presented in [4]. The two main processrelated challenges are the huge amount of energy used and $\mathrm{CO}_{2}$ emissions. The energy usages are technologydependent and may be characterized as exergy destruction.

Figure 4 shows the main environmental challenges for the silicon production according to [5]. Most challenges may be addressed through technical improvements. The high need for electrical energy and $\mathrm{CO}_{2}$ emissions may be mitigated through future process - society integration simply because a fully electrified society will generally be more energy efficient, e.g. if process cooling water is utilized for heating purposes, and provided the electric power is solar based the $\mathrm{CO}_{2}$ emissions are also drastically reduced.

The exergy destruction in the silicon process was presented by Takla [6]. Figure 5 shows a very huge span in exergy efficiency, from silicon production based on electrical energy from coal $\left(\mathrm{E}_{\mathrm{e}}=0.18\right)$ to a theoretically good use of all excess energy $\left(\mathrm{E}_{\mathrm{e}}=0.75\right)$.

Pure silicon dioxide and carbon (graphite) are added to the furnace together with electrical energy. The furnace reaction is a modified version of $\operatorname{Rx}(1)$ due to the fact that some of the silicon input is leaving the furnace as $\mathrm{SiO}(\mathrm{g})$ :

$$
\begin{gathered}
(1+x) \mathrm{SiO}_{2}+(2+x) \mathrm{C}=\mathrm{Si}+\mathrm{xSiO} \\
+(2+x) \mathrm{CO} . \quad{ }^{\prime \prime} \mathrm{Rx}(1)^{\prime \prime}
\end{gathered}
$$

The enthalpy and the entropy of this reaction are both positive (Tab. 1). The theoretical amount of electrical energy needed to produce one mole of silicon is determined from the enthalpy of the furnace reaction. The amount of electrical energy added to the furnace is referred to as the furnace power. There are no losses in the electrical supply system, and no thermal energy losses from the furnace to its

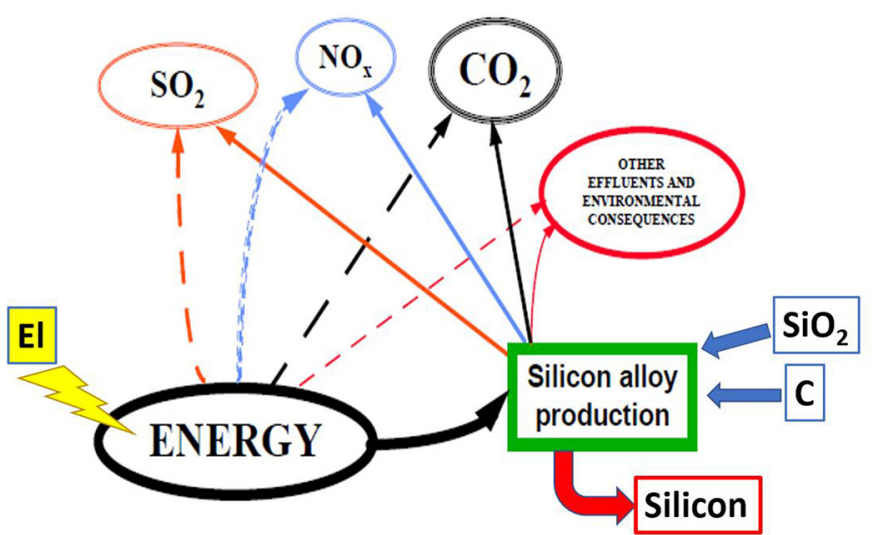

Fig. 4. Main environmental challenges for the silicon production [5].

surroundings. We assume a temperature of $1400^{\circ} \mathrm{C}$ for the gas ( $\mathrm{SiO}$ and $\mathrm{CO}$ ) leaving the top of the furnace. Liquid silicon leaves the bottom of the furnace at a temperature of $1600{ }^{\circ} \mathrm{C}$. The silicon yield $\mathrm{s}$, where $0 \leq \mathrm{s} \leq 1$, is the amount of silicon fed as quartz that produces silicon metal. The yield relates to the reaction parameter $\mathrm{x}$ defined by $\mathrm{s}=1 /(1+\mathrm{x})$.

The most common process today is the first one shown in Figure 5, with coal-based electricity and no energy recovery. The best available industrial technology (BAT) is at a silicon yield at 0.9 with energy recovery which suggest an exergy efficiency at around 0.7 .

Table 6 shows the exergy calculation for a silicon production based on hydropower, with silicon yield $100 \%$ but no energy recovery. New computer programs such as HSC 9.0 make calculations of exergy easy. In this particular case, the exergy yield is $52.5 \%$.

Combining the information in Figures 3, 4 and 5, the measures that can improve the silicon process standard will be:

- production of electrical energy without $\mathrm{CO}_{2}$ emission;

- use of biological carbon as reducing agent;

- a silicon process with low energy losses and high silicon yield;

- energy integration or energy recovery - utilizing the high-quality energy sources in subprocess III and IV in Figure 3;

- future closed cooling air circulation in step III in Figure 3 or circulating the off-gas after the boiler may increase the $\mathrm{CO}_{2}$-content in the off-gas - and Carbon capture and storage (CCS) or Carbon capture and usage (CCU) may then be introduced;

- closed furnace with zero or little combustion of the process gas.

All silicon furnaces are in order to secure access for maintenance and possible manual feeding, normally operated as open or semi-closed - and with immediate combustion of CO-gas and SiO-gas. Measures 1-4 above are technically possible - but may have economic constraints. Measures 5 and 6 are not proven technology and there are severe technical challenges to overcome for implementing them. 


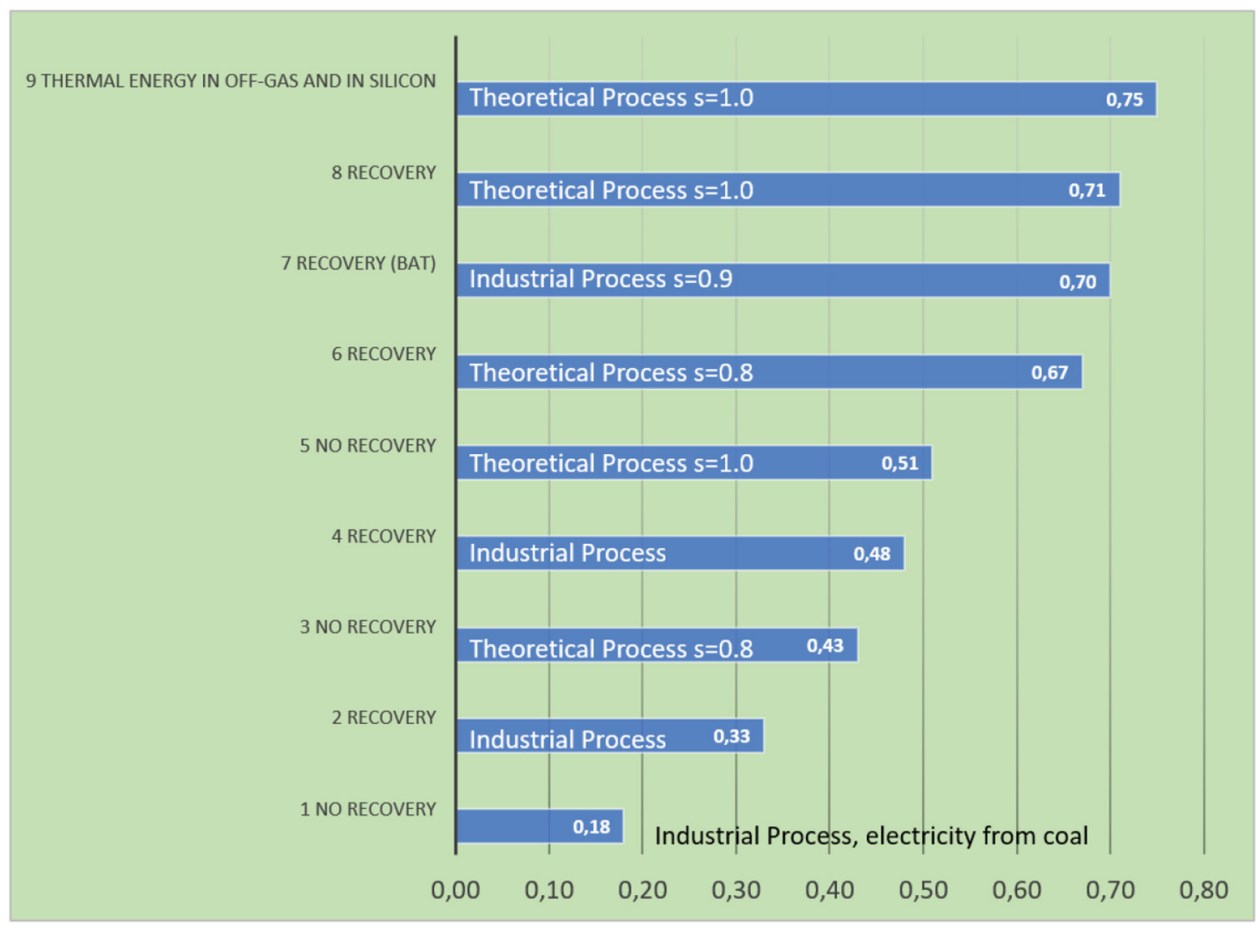

Fig. 5. Exergy efficiency for silicon production.

Table 6. Calculation of exergy for simplified silicon production process.

\begin{tabular}{|c|c|c|c|c|c|c|c|c|}
\hline Streams and species & $\begin{array}{l}\text { Mass } \\
(\mathrm{kg})\end{array}$ & $\begin{array}{l}\text { Amount } \\
(\mathrm{mol})\end{array}$ & $\begin{array}{l}\text { Molfraction } \\
\text { (fraction) }\end{array}$ & $\begin{array}{l}\mathrm{T} \\
{ }^{\circ} \mathrm{C} \\
\end{array}$ & $\mathrm{P}$ (bar) & $\begin{array}{l}\text { H total } \\
(\mathrm{kJ})\end{array}$ & $\begin{array}{l}\text { Ex_tot } \\
\text { stream } \overline{(k J)}\end{array}$ & $\begin{array}{l}\text { Exergy } \\
\text { efficiency (\%) }\end{array}$ \\
\hline Input stream 1 & 0.12 & 4.00 & 1.00 & 25.00 & 1.00 & -911 & 827 & \\
\hline $\mathrm{SiO}_{2}$ & 0.06 & 1.00 & 0.25 & 25.00 & 1.00 & -911 & & \\
\hline $\mathrm{C}$ & 0.02 & 2.00 & 0.50 & 25.00 & 1.00 & 0 & & \\
\hline $\mathrm{O}_{2}(\mathrm{~g})$ & 0.03 & 1.00 & 0.25 & 25.00 & 1.00 & 0 & & \\
\hline Input energy stream 1 & & & 877 & 877 & & & & \\
\hline Heat feed & & 0.00 & 0.00 & & & & & \\
\hline Electricity feed & & 0.00 & 877 & & & & & \\
\hline Output stream 1 & 0.12 & 3.00 & 1.00 & 25.00 & 1.00 & -787 & 895 & \\
\hline $\mathrm{CO}_{2}(\mathrm{~g})$ & 0.09 & 2.00 & 0.67 & 25.00 & 1.00 & -787 & & \\
\hline $\mathrm{Si}$ & 0.03 & 1.00 & 0.33 & 25.00 & 1.00 & 0 & & \\
\hline Output energy stream 1 & & & 753 & 0 & & & & \\
\hline Heat loss & & 25.00 & 753 & & & & & \\
\hline Electricity out & & & 0 & & & & & \\
\hline Total efficiency & & & & & & 0.00 & 809 & $52.5 \%$ \\
\hline
\end{tabular}

\section{Some thoughts about silicon production and the future}

The authors assume that coming generations will also have to obey the basic thermodynamic law and that silicon will have to be produced. Hopefully, new knowledge and technologies will develop processes with even higher environmental standards. Today's Best Available Technology (BAT) [10] is production based on biological carbon and with a high degree of energy recovery. Energy integration should be a part of the decision basis when planning new silicon plants.

Table 7 shows some scenarios for silicon production. There is good agreement with the 2 calculations with no energy recovery. The "Substitute electrical use" case is not real - but it shows very clearly the effect of energy 
Table 7. Energy scenarios for silicon production.

\begin{tabular}{llll}
\hline Energy usage - process & Electrical energy & Exergy efficiency & Reference \\
\hline No energy recovery & Coal & $18 \%$ & Takla \\
No energy recovery & Hydro & $51 \%$ & Takla \\
No energy recovery & Hydro & $52 \%$ & HSC \\
Energy recovery & Hydro & $73 \%$ & HSC \\
Substitute el use & Hydro/Energy swop & Very high & HSC \\
\hline
\end{tabular}

integration between process industry and other users of energy that may replace electrical energy produced from fossil fuel.

The total entropy change of the $\mathrm{Si}$-production system is made up of a reaction part and an energy transfer part: $\Delta \mathrm{S}_{\mathrm{sys}}=\Delta \mathrm{S}_{\mathrm{reac}}+\Delta \mathrm{S}_{\text {trans }}$. This entropy production exactly describes the associated resource use in the production process. Loosely speaking, the 'ordered' form of energy stored within the chemical structure of the raw materials has been 'set free' and has thereby become 'disordered'. More physically speaking, the system after the various subprocesses has more available microstates than the system before the process took place, but its energy has not changed. This is nothing else but a rephrasing of the second law of thermodynamics. The increase in available microstates is measured by the amount of produced entropy. But what was really 'used up'? The use of the resources carbon, electricity, quartz and air cannot really be linked to the number of atoms, the total energy or the mass of the substances, since these quantities have not changed from the initial to the final state.

What has changed, however, is the ability of the system to perform work on the environment. The partial loss of this ability is what we really mean when we say a resource was 'used'.

All processes of change are generally processes of energy and material transformation and the entropy concept applies to all of them. Entropy thus creates a unifying perspective on ecology, the physical environment and the economy. On a more specific level, the entropy concept is essential for understanding to what extent resource and energy scarcity, nature's capacity to assimilate human wastes and pollutants, as well as the irreversibility of transformation processes, constrain economic action, e.g. for the presently very popular Circular Economy. On an even more applied level, the entropy concept provides a tool of quantitative analysis of energetic and material transformations for engineers and managers. It may be used to design industrial production plants or their individual components, for example to maximize their energetic efficiency and to minimize their environmental impact.

With its character as an analytical tool, its multitude of applications, and its obvious potential to establish relations between the natural world and purposeful human action, the entropy concept is one of the cornerstones of future human development [1].

Using entropy in thermodynamic calculations and even understanding the derived results from such exercises are routinely done by metallurgists as shown in this paper; and we love it!
To really understand the concept of entropy, or for that matter the concept of energy is however a different matter. According to Joshua Floyd [7], Dr. Frank Lambert, Professor Emeritus (Chemistry) at Occidental College, Los Angeles [8], has for many years been working to amend the popular (and, in many cases, specialist) misunderstanding of the second law. Lambert's efforts have resulted in at least 15 prominent chemistry textbooks being revised to replace the "order to disorder" metaphor with an updated definition based on energy dispersal. He also reports that the eighth edition of the worldwide best-selling textbook on physical chemistry, Atkins's Physical Chemistry, has been revised to significantly reduce emphasis on order-disorder, emphasising instead this energy dispersal metaphor. In the revised texts:

- the second law of thermodynamics is defined as the tendency for energy to spontaneously disperse within a thermodynamic system, or from a thermodynamic system to its surrounds, unless it is hindered from doing so [8];

- thermodynamic entropy is then defined as the measure of the energy so dispersed, at a given temperature [8].

As described by Floyd [7]: "Energy is an abstract concept that we have constructed in order to describe and understand the activity, or the behaviour, that we observe in the course of our interactions with material systems. Energy is not a thing or a substance: it is a conceptual construct that assists us to make sense of our experiences relating to the activity of things or substances". And further: "Entropy, then, is an abstraction of an abstraction: it is an abstract concept that we have created to describe and understand the condition of material systems resulting from the activity of these systems that we describe in terms of energy-enabled causation. That is, entropy is a conceptual construct that assists us in describing the change in condition of material systems as a result of the activity within those systems, and interactivity between systems. The second law describes a general principle relating to the activity of activity of things, specifically as this manifest in thermodynamic systems."

Having tried to understand metallurgical literature involving deliberations of entropy have been a useful struggle, and it is enjoyable to see that prominent scientists in other fields also have made use of this entropy concept in order to explain complex processes in economy, sociology, etc. But when it turns out that most of these people have misinterpreted the concept and applied it in wrong ways it is mildly irritating, however, this feeling may easily turn 
into hate when we realize the possibility of own misunderstandings of the role of entropy related to own research and teaching.

Acknowledgements. This publication has been funded by Elkem and NTNU and supported by Research Domain 5 - Materials and Society in SFI Metal Production, (Centre for Research-based Innovation, 237738). The authors gratefully acknowledge the financial support from the Research Council of Norway and the partners of the SFI Metal Production.

\section{References}

1. S. Baumgärtner, "International Society for Ecological Economics Internet Encyclopaedia of Ecological Economics", 2003.

2. BP Energy Outlook, 2019. https://www.bp.com/en/global/ corporate/energy-economics/energy-outlook.html/.

3. Outotec HSC Chemistry Software HSC version 9.0, https:// www.outotec.com/products/digital-solutions/hsc-chemistry/.
4. Schei, Tuset, Tveit. Production of high silicon alloys. ISBN 82-519-1317-9 Tapir publisher, Trondheim, 1998.

5. N.E. Kamfjord, E.H. Myrhaug, H. Tveit, B. Wittgens, "Energy balance of a 45-MW (ferro-) silicon submerged arc furnace". INFACON XII Helsinki Finland, 2010.

6. M. Takla, N.E. Kamfjord, H. Tveit, S. Kjelstrup, "Energy and exergy analysis of the silicon production process", Energy 58, 138 (2013), DOI: 10.1016/j.energy.2013.04.051.

7. J. Floyd, Thermodynamics, entropy and disorder in futures studies, Futures 39(9), 1029 (2007), DOI: 10.1016/j.futures. 2007.03.011.

8. F. Lambert, A student's approach to the second law and entropy, 2005, http://entropysite.oxy.edu/students_approach. html.

9. The United Nations Climate Change Paris agreement, https://unfccc.int/process-and-meetings/the-paris-agreement/ the-paris-agreement/.

10. G. Cusano, M.R. Gonzalo, F. Farrell, R. Remus, S. Roudier, L. Delgado Sancho, "Best available techniques (BAT) reference document for the main non-ferrous metals industries", EUR 28648, DOI: 10.2760/8224. https://eippcb.jrc.ec.europa.eu/ reference/BREF/NFM/JRC107041_NFM_bref2017.pdf.

Cite this article as: Halvard Tveit, Leiv Kolbeinsen, The (love \& hate) role of entropy in process metallurgy, Matériaux \& Techniques 107, $506(2019)$ 